\title{
Act now on antibiotic resistance
}

To the editor-In your May issue, The Brockham Group discussed the growing problem of antimicrobial resistance. The group concluded that research towards a better understanding of the problem is necessary before specific recommendations on prescribing habits can be given ${ }^{1}$. We are concerned that this course will delay much-needed initiatives to improve the quality of antibiotic prescribing.

The role of antibiotic resistance is not absolute in determining clinical outcome, which is based on multifactorial elements. Resistance is only relative (or microbiological) in many instances. Often, disease caused by such variant organisms will respond to antibiotics but perhaps only with high-dose therapy. Resistance obviously related to treatment failure and/or poor patient outcome can usually be understood in scientific terms and vice versa. There is no mystery about the response of bacteria (sensitive or resistant) to antibiotics, despite the complexity of the in vivo situation.

Similarly, although we are only beginning to understand the intricacies of the development of bacterial resistance in response to antibiotic exposure, it has been obvious for 50 years that antibiotic use leads, sooner or later, to resistance. Many factors can magnify this problem-most importantly, cross-infection. However, despite the role of integrons and transposons, careful prescribing can reverse the current alarming resistance trends ${ }^{2}$.

We cannot afford to wait for the results of (important) research, as suggested, but must act now to restrict antibiotic use. Although current knowledge levels are imperfect, if we keep sight of the basics, we probably know enough to act now in sensible ways. When (value judgement or cost/benefit), where (animal husbandry, community, hospital) and how (which control measures/education) are the essential questions that should be addressed immediately.

It is also essential to gain the support of management and the medical hierarchy, and to convince bureaucrats and politicians to provide more resources. The current activities of Britain's House of Lords ${ }^{3}$ and the promised debate in the House of Commons are promising developments, and we commend the CDC (Centers for Disease Control, Atlanta, Georgia, USA) Strategic Goals $s^{4}$. The World Health Organization and the European Commission are also moving on this. Ultimately, however, the education and motivation of individual doctors and their patients to accept the responsibility for good prescribing habits backed by appropriate investigation isfundamentally important. An essential element, often forgotten in this equation, is hospital hygiene and, unfortunately, economies in heal th care budgets, with the concomitant loss of nursing staff and beds, seriously compromise efforts to control the spread of resistant organisms.

The Brockham Group conclude that there is not yet sufficient understanding to support any specific prescribing or control policies and that a comprehensive research effort is needed before we set in place appropriate policies. Although we join with them in calling for more research resources, we firmly believe that enough is known about antibiotic useand abuse, its consequences and how to control it, to allow us to act now on a broad front before it becomes too late.

IAN M. GOULD \&

Jos W. M. VAN DeR Meer

On behalf of the European Society for Clinical

Microbiology and Infectious Diseases Antibiotic Policy Study Group.

1. Bax, R.P. et al. Antibiotic resistance - what can we do? Nature M ed. 4 545-546 (1998).

2. White, A.C. et al. Effects of requiring prior authorisation for selected antimicrobials; expenditure, susceptibilities and clinical outcomes. Clin. Infect. Dis. 25 230-239 (1997).

3. Select Committee on Science and Technology. Resistance to antibiotics. House of Lords: Session 1997-1998, 7th Report.

4. Goldmann, D.A. et al. Strategies to prevent and control the emergence and spread of antimicrobialresistant microorganisms in hospitals. J. Am. Med. Assoc. 275 234-240 (1996).

The Brockham Group replies-Our major message is that in order to manage the problem and produce effective policies, it is paramount to quantify antibiotic resistance. Statements such as "we cannot afford to wait for the results of research but must act now to restrict antibiotic use" and "if we wait it will surely be too late" are not helpful without quantifying the risk benefit. These data are also needed in order to decide on the scale of the change needed to maintain the public health. Doing something simply for the sake of appearing to take action may not be wise.

\section{RICHARD BAX}

SmithKline Beecham Pharmaceuticals New Frontiers Science Park (South)

Harlow, Essex CM 19 5AW, UK

On behalf of the Brockham Group 